\title{
Ciberativismo e a Dimensão Comunicativa dos Movimentos Sociais: repertórios, organização e difusão
}

Livia Moreira de Alcântara'

\section{Resumo}

Importantes atualizações das Teorias dos Movimentos Sociais a partir dos aspectos comunicativos da ação coletiva vêm sendo realizadas em torno das discussões referentes ao ciberativismo - reduzindo o abismo existente entre os estudos em comunicação e movimentos sociais. No entanto, boa parte dos trabalhos pode ser caracterizada por um foco excessivo nas tecnologias e pela instrumentalização da noção de comunicação. Esse artigo repensa as teorizações da ação coletiva e dos movimentos sociais a partir da comunicação, realizando dois esforços: primeiro por meio de uma análise de caráter histórico, que busca demonstrar a centralidade da dimensão comunicativa nas práticas dos movimentos sociais em momentos anteriores a internet, construindo uma perspectiva não instrumental da comunicação; segundo, propõe uma interpretação de viés teórico que possibilita olhar de forma integrada para três eixos analíticos das teorias da ação coletiva e dos movimentos socais: os repertórios de ação coletiva, os processos de organização e as dinâmicas de difusão.

Palavras-chave: Ciberativismo. Comunicação digital. Movimentos sociais. Sociologia dos movimentos sociais.

\section{Ciberativismo e as Teorias dos Movimentos Sociais}

Desde a década de 90, as açóes coletivas e os movimentos sociais têm sido transformados pelas possibilidades de comunicação via internet e outras novas tecnologias da comunicação e da informação (NTICs). Ocupações virtuais de sites de corporaçôes ou governos, açóes hackers, petiçóes on-line, mobilização e coordenação de protestos através da utilização da internet, cobertura jornalística alternativa e digital, são alguns exemplos. Assim, a utilização de NTICs pelos movimentos sociais, vem "mudando a maneira pela qual os ativistas

Doutoranda em Sociologia pelo Instituto de Estudos Sociais e Políticos da Universidade Estadual do Rio de Janeiro (IESP/UERJ). 
comunicam, colaboram e manifestam" (GARRETT, 2011, p. 2002). Embora esses processos recebam nomeaçôes distintas, podem ser agrupados em torno do nome ciberativismo, entendido de forma ampla, como a utilização de NTICs por movimentos sociais e ativistas.

Compreender como a utilização da comunicação digital vem alterando as dinâmicas da ação coletiva e dos movimentos sociais tem se tornado, assim, uma questáo importante para os atores e um desafio para o campo científico. Algumas contribuiçóes instigantes têm sido realizadas buscando superar a lacuna existente entre os estudos de comunicação e as teorizaçóes sobre a ação coletiva e os movimentos sociais. Nas Teorias dos Movimentos Sociais, a comunicação foi uma dimensão pouco explorada e abordada de forma problemática. Quase sempre lançou-se mão de uma concepção instrumental da comunicaçáo, que a restringiu aos instrumentos tecnológicos utilizados pelos atores para executarem suas metas (CARROLL; HACKETT, 2006; DOWNING, 2008; MAIA, 2009; TRERÉ, 2014)².

Recentemente, contribuiçóes interessantes têm surgido a partir de uma atualização dos conceitos das teorias da ação coletiva e dos movimentos sociais no contexto de comunicação digital, gerando termos como esfera pública interconectada (LANGMAN, 2005) e repertórios de ação digital (LAER; AELST, 2010). Embora essas teorizaçóes coloquem debates importantes, elas têm sido construídas de forma rígida e muitas vezes instrumentalizando a noção de comunicação a partir de um foco excessivo na tecnologia em si. Langman (2005) reifica a internet, como um espaço no qual as pessoas negociam entendimentos, consensos, críticas, propóem alternativas e realizam metas; reifica também os "movimentos sociais interconectados" como atores que por si só são descentralizados, democráticos e difíceis de serem controlados. Laer e Aelst (2010), apesar de contribuírem com uma descrição dos repertórios de ação do Movimento Antiglobalizaçáo, propóem uma interpretaçáo baseada em uma distinção rígida entre espaço on-line e off-line e referenciada mais nas tecnologias do que no uso/criatividade dos atores. Pereira (2008) possui um

2 Como exceção podemos citar alguns autores desenvolveram abordagens mais complexas da comunicação, como Atton (2002) que versou sobre a relação entre comunicação e estrutura organizativa dos ativistas; Downing et al. (200I) que propõem pensar a comunicação em seus múltiplos formatos; e Peruzzo (2004) que investiga movimentos de comunicação comunitária e popular no contexto de lutas democráticas latino-americanas. 
trabalho de fôlego nesse sentido, buscando repensar as teorias sobre democracia a partir dos "novos repertórios do cyberativismo". Embora o autor se concentre nos repertórios, o seu trabalho mostra como esses são indissociáveis de outras dimensôes da ação coletiva, como organização, por exemplo.

As velhas divisões entre uma análise mais focada na organização e outra na identidade coletiva, pertencente aos embates entre a Teoria da Mobilizaçáo de Recursos e as Teorias dos Novos Movimentos Sociais, também têm sido recuperadas a partir de uma abordagem das tecnologias comunicacionais digitais. Bennett e Segerberg (2012) têm sido os principais expoentes de uma tentativa de recuperação dos eixos temáticos da Teoria da Mobilização de Recursos com sua teoria da "ação conectiva", na qual propóem entender as redes socais e as novas plataformas de comunicaçáo como estruturas organizativas. Os autores reproduzem alguns problemas da perspectiva estadunidense sobre os atores, como a demasiada atenção ao envolvimento individual na ação coletiva.

Autores críticos a essa perspectiva têm apontado que as redes sociais digitais também contribuem para a geração de "identidade coletiva" (GERBAUDO; TRERÉ, 2015). Esses trabalhos possuem o mérito de olhar para a ação coletiva e para as mídias sociais desde uma perspectiva simbólica, pouco abordada nos estudos mais recentes. No entanto, acabam reforçando uma separação entre organização e simbólico que faz pouco sentido desde a realidade desses atores. Há ainda o livro Mediation and Protest Movements, organizado por Cammaerts et al. (2013), que propóem pensar as novas tecnologias da comunicaçáo a partir da noção de mediação e não como meros instrumentos.

A despeito de importantes contribuições como essas, parte significativa das pesquisas possui um foco excessivo nas tecnologias em si. Isso resulta, por um lado, em descriçóes isoladas de casos de apropriaçóes político-tecnológicas; e, por outro, em análises inteiramente baseadas em dados das redes sociais digitais, sem um aprofundamento nas interaçóes e contextos políticos.

Em diálogo com as contribuiçóes existentes e ciente de que avanços nessa direção ainda são necessários para uma melhor compreensão do papel da comunicação digital nas dinâmicas dos conflitos societários contemporâneos, esse trabalho lança mão de um olhar transversal e histórico para diferentes eixos e dimensóes das práticas dos atores. $\mathrm{O}$ objetivo aqui é propor uma 
discussão ampla de como a dimensão comunicativa dos movimentos sociais e da ação coletiva foi abordada nas teorizaçóes sobre esses temas, complexificando as abordagens mais recentes sobre o ciberativismo.

Para tanto, propóe-se um duplo esforço. Por um lado, uma análise de caráter histórico, que permita identificar a centralidade da dimensão comunicativa nas práticas dos movimentos sociais - através do resgate de contextos anteriores à popularização da internet. Por outro lado, propóe-se uma interpretação de viés teórico, que possibilite resgatar alguns eixos/dimensóes de análise das teorias das açóes coletivas e dos movimentos sociais, de tal forma que ferramentas analíticas possam ser atualizadas para o entendimento do ciberativismo. Para a operacionalização da análise teórica optou-se por selecionar três elementos centrais das práticas e teorias dos movimentos sociais, que ajudam a compreender as dinâmicas comunicativas da açáo coletiva ao longo do tempo, quais sejam: os repertórios de ação coletiva, os processos organizativos e as dinâmicas de difusão. $\mathrm{O}$ artigo está estruturado em torno desses três itens. Outras dimensôes poderiam ter sido selecionadas, porém tal tarefa seria inadequada para o escopo desse trabalho.

\section{Repertórios de ação coletiva}

A noção de repertórios de contestação foi trabalhada por Charles Tilly em várias obras e sofreu redefiniçóes ao longo delas. Resumidamente, designa o conjunto limitado de formas que os atores sociais dispóem e compartilham em determinado momento histórico para externar suas demandas. São exemplos de repertórios as marchas, boicotes, petiçóes e greves. Os repertórios são assim criaçóes culturais que emergem na luta política, no confronto entre os atores sociais. "O confronto político não nasce da cabeça dos organizadores, mas está culturalmente inscrito e é socialmente comunicado" (TARROW, 2009, p. 30). Segundo Tilly (1978, 2006), os repertórios sofrem pequenas variaçóes ao longo do tempo, sendo essas inovaçôes relacionadas à organização e à estrutura da sociedade, aos laços sociais, às oportunidades e restriçôes políticas e ao aprendizado em ações coletivas prévias.

A importância dos repertórios está no fato de que eles constituem a parte mais visível da ação coletiva (BRINGEL, 2012; MELUCCI, 1989), embora se configurem nas açôes cotidianas dos atores inseridos da luta política. As formas de ação possuem assim uma dupla dimensão comunicativa (externa e 
interna). Por um lado, são a forma pela qual os movimentos sociais colocam em pauta seus objetivos e reivindicaçóes para a sociedade e para o Estado visibilizando as características da açáo coletiva e do confronto político. E em um sentido interno, os repertórios são produtos da contínua elaboração dos atores, que diante dos contextos e dos desafios políticos, inovam e adaptam as formas de ação para alcançarem seus objetivos. Possuem, também, um papel no desenvolvimento da identidade do grupo, uma vez que expóem publicamente os polos do conflito, permitindo as pessoas se identificarem com um ou outro lado da questáo em jogo. A partir de dois exemplos iremos trabalhar essa dimensão comunicativa dos repertórios, a fim de iluminar as discussóes sobre os "repertórios ciberativistas".

O primeiro desses repertórios são as greves. Essas surgiram como um processo de resistência dos trabalhadores e, aos poucos, foram se tornando um instrumento proativo (TILLY, 1978). Alguns elementos comunicativos das greves podem ser ressaltados. Em primeiro lugar, é interessante notar que, como forma de expressão do descontento dos trabalhadores, a paralisação da produção "garante" a abertura de uma negociaçáo com o patrão, instaura a possibilidade de que as reivindicaçóes sejam questấo de diálogo entre as partes.

Além disso, a estrutura particular para que a paralisação do trabalho ocorra depende do comportamento das múltiplas partes envolvidas no conflito: do patrão, dos sindicatos, do governo (TILLY, 1978) e dos trabalhadores. A greve tem assim uma dimensão relacional. Por exemplo, os laços entre as organizaçóes trabalhistas e os governos as afetam fortemente. Se as organizaçóes trabalhistas se fortalecem, estabelecem boas relaçóes com os governos e adquirem controle das açóes coletivas, as greves tornam-se relativamente custosas para as empresas; porém, na medida em que o governo diminui sua intervençáo, a força das greves passa a depender do ritmo da economia (TILLY, 1978). A relação entre estes atores não se dá de forma horizontal. Os sindicatos são mediadores, possuem o papel de convocar as greves e de realizar a negociação entre as reivindicaçóes dos trabalhadores e as contrapropostas dos patróes. O Estado, por sua vez, também pode mediar esta situaçáo adotando medidas que favoreçam um ou outro lado. Dessa forma, a greve é construída na interação do confronto, que se dá mediante reunióes, abaixo-assinados, circulares, dentre outras rotinas de comunicaçáo. Entender a greve como produto das interaçóes entre estes quatro atores evidencia o caráter relacional e comunicacional deste repertório. 
Um segundo exemplo que aporta a essa discussão, está presente nos estudos de Sader (1988), sobre os movimentos populares brasileiros na grande São Paulo, no final da década de 1970. A partir de uma perspectiva interna, o autor mostra como os repertórios são construídos pelos atores no cotidiano da luta e são frutos de um aprendizado. Nesse sentido, um exemplo ilustrativo é o caso do movimento de saúde da periferia leste da metrópole, que emerge a partir das Comunidades Eclesiais de Base. Inicialmente centrado na caridade cristá dos grupos católicos, o movimento amadureceu, passando para uma fase ancorada na reivindicação de um direito (SADER, 1988) - o que fica evidente na mudança dos repertórios de ação coletiva. O primeiro passo para essa mudança foi a constatação de que as formas de açóes empregadas não eram suficientes para a transformação da realidade, ou seja, de que as péssimas condiçôes de saúde do bairro não seriam resolvidas com as ações de caridade (como dar dinheiro para as mães levarem os seus filhos em postos de saúde que estavam longe de suas residências). Ao mesmo tempo, a população do bairro começou a tomar contato com médicos sanitaristas, que traziam informaçóes sobre os serviços de saúde. Partiu-se então para a realização de pesquisas de bairro e de abaixo-assinados, tornando o problema uma demanda coletiva e encaminhando-o como uma reivindicaçáo (um centro de saúde no bairro) ao poder público. Nesse caso, a experiência dos problemas de saúde, as tentativas de resolvê-los e o contato com outras possíveis soluções, em conjunto, foram alterando as formas de ação do movimento e implicando, inclusive, em novas formas de organização.

Com esses dois exemplos, o que se quer ressaltar é que através das interaçôes e relaçóes mediadas comunicativamente, os atores, inseridos no confronto político, constroem e modificam os próprios repertórios. Os repertórios são forjados sempre por um conjunto de atores em disputa (TILLY, 1993), sendo assim, sempre produto de relaçóes sociais e interaçóes comunicativas, sejam elas mediadas por tecnologias ou não. No entanto, esta perspectiva comunicacional e relacional dos repertórios nem sempre esteve e está presente nas análises. Com base nessa perspectiva aqui desenvolvida, gostaríamos de apontar alguns problemas sobre as análises dos "repertórios ciberativistas".

Segundo as análises contemporâneas, esses surgem a partir da década de 1990 e compreendem tanto aqueles repertórios que se materializam no ambiente digital (petiçôes on-line, ocupaçóes virtuais de sites etc.), como 
também outros que possuem suas dinâmicas alteradas pela comunicação digital (como é o caso dos símbolos e ideias que ganham rápida difusão através da comunicação via internet). O trabalho de Laer e Aelst (2010) é ilustrativo nesse sentido, dado que os autores fazem um inventário dos "repertórios de açóes digitais". A tipologia proposta por eles se baseia em duas características: nível de dependência da internet e custo de participação. As açóes podem ser "suportadas pela internet" (ex: doação de dinheiro e encontros transnacionais) ou "baseadas na internet" (ex: petiçôes online e hacktivismo); as ações podem exigir um "baixo custo de participação" (boicotes de consumo) ou um "alto custo de participação" (ocupação do espaço físico). Essa tipologia está ancorada e reforça duas binaridades: entre o ambiente on-line/off-line e entre laços fracos/laços fortes - que também está presente em outros estudos sobre o assunto, como no texto bastante conhecido $A$ revolução náo será tuitada, de Gladwell (2010). De forma sucinta se pode afirmar que outras pesquisas têm apontado para a complementaridade entre os ambientes on-line e off-line (BOASE; WELLMAN, 2006) e para a importância dos laços fracos na internet, que desempenham certo papel de difusão das ideias, das açôes e notícias sobre movimentos (ROVIRA, 2009). Assim, essas binaridades, que têm sido amplamente reproduzidas nos estudos da área, ajudam pouco a compreender as reconfigurações das práticas dos atores.

Outra tensão que costuma perpassar os estudos é entre os repertórios criados a partir da utilização dos meios de comunicaçáo dos próprios movimentos e os repertórios que nascem a partir da interação com a mídia mainstream como se os ativistas fizessem uso de apenas uma tecnologia e uma estratégia de comunicação em cada caso (TRERÉ, 2014). Mattoni (2013), a partir da noção de "repertórios de comunicação" indica alguns caminhos para enfrentar esse problema. A autora aponta como os ativistas aprendem as práticas midiáticas que empregam e como desenvolvem suas práticas, a partir de uma interação e uma relação com as tecnologias de mídia, com os meios de comunicação e com os profissionais de mídia.

Diante da crítica aqui realizada e da noçáo relacional e comunicacional de repertórios desenvolvida, dois principais desafios teóricos podem ser ressaltados. O primeiro é a passagem da noção de repertório baseada na utilização de uma nova tecnologia para uma problematização mais relacional do desenvolvimento das formas de ação, considerando as interaçóes entre os atores e os 
processos de aprendizado entre os ativistas e movimentos. Como reforça Tilly (2006), a adoção de uma nova tecnologia não gera um novo repertório por si só, estas são submetidas aos usos sociais e não o contrário. O segundo desafio refere-se à necessidade de gerar abordagens que não realizem uma separação entre os ambientes on-line e off-line, integrando tanto uma análise das ferramentas, algoritmos e dados digitais, quanto dos contextos, relaçóes políticas, histórico das lutas e dos atores.

\section{Organização}

A noção de organização é ambígua, sendo utilizada para designar uma organização formal (instituição, movimento social, empresa) ou para se referir aos processos organizativos que se dáo dentro de um tipo de organizaçáo. Para Kavada (2013), a organizaçáo dos movimentos sociais está relacionada a alguns métodos e estruturas, como: ao grau de formalidade (formal/informal); ao grau de centralizaçáo (centralizado/ descentralizado/distribuído); ao grau de hierarquia (hierárquico/horizontal); ao grau de profissionalização (profissional/voluntário); à liderança e às linhas de controle (de cima para baixo e de baixo para cima).

A natureza comunicacional dos processos organizativos está no fato de que eles envolvem uma série de funçóes informacionais e comunicacionais como: identificar os interesses e as preocupaçóes das pessoas, contatá-las para seus propósitos e desenvolver identidade coletiva, estabelecer agenda, coordenar ação e o engajamento (BIMBER; STOHL; FLANAZIN, 2009). Bennett e Segerberg (2012) argumentam que as redes digitais possuem uma natureza eminentemente comunicativa e interativa, que transforma a lógica de organização da ação coletiva. Essa discussão nos leva a questionar: os processos organizativos náo estiveram sempre moldados pelas dinâmicas de comunicação?

Diferente da estratégia utilizada na seção anterior, de realizar um esforço por ressaltar uma dimensáo comunicativa dos repertórios, nessa parte, pretende-se apontar como, ao longo do tempo e em diferentes abordagens, a concepçáo de comunicação (nem sempre explícita) esteve relacionada à noção de organização. Argumenta-se que essa relação foi estabelecida percebendo-se a comunicação a partir da organização e que, nos últimos 20 anos, com o crescimento das pesquisas relacionadas à internet, essa leitura tem sido invertida. A organização tem sido concebida, em boa parte das pesquisas, a partir 
das práticas comunicativas dos movimentos sociais. Essa mudança revela, por um lado, uma maior atenção à dimensão comunicativa da organização; mas por outro, a organizaçáo tem sido reduzida ao engajamento individual nas plataformas midiáticas. Para discutir essas questóes, recuperamos aqui alguns marcos históricos desse debate.

Uma das primeiras abordagens sobre o tema, está presente nos escritos Que fazer?, de Lenin (1902). Nesse, o autor e militante destaca a comunicação como um componente importante da organizaçáo política, sendo um eixo articulador entre teoria e prática revolucionária. Lenin (1902) concebeu três principais instrumentos que facilitariam essa articulação: a agitação, a propaganda e o jornal. No que tange à propaganda e agitaçáo, o autor diferenciava ambas, sendo a primeira relacionada à tarefa de explicaçáo da teoria revolucionária às massas em geral; e a segunda referente à incitaçáo dos proletários a intervir na realidade a partir de atos concretos. Assim, ambas se relacionam com o papel dos intelectuais do "partido de quadros" na educação política das massas e apresentam-se como atividades complementares - conectando teoria e prática revolucionárias.

Além da agitação e da propaganda, Lenin (1902) atesta a necessidade de criação de um meio de comunicação unificado para toda a Rússia. Para ele, o jornal unificado teria a função de fazer a conexão entre os processos e causas revolucionárias de diferentes cidades, possibilitando a troca de informaçóes e experiências, forças e recursos. Além disso, potencializaria o trabalho de organização do próprio partido, uma vez que a rede de agentes para realização de um jornal seria um comitê preparado para intervir em casos de insurreição. "O jornal não é apenas um propagandista coletivo e um agitador coletivo; é também um organizador coletivo" (LENIN, 1902, p. 87). Em Lenin (1902) a comunicação possui uma função pedagógica e de conexáo entre os núcleos do partido comunista. O que se destaca dessa perspectiva é que a comunicação não está separada da própria estrutura organizacional do partido de vanguarda. Ao contrário, sustenta-o ao mesmo tempo em que serve aos seus propósitos e lógica.

Já a Teoria da Mobilização de Recursos (TMR) concebeu a comunicação como um recurso que as organizaçóes necessitam mobilizar para intervir nos debates públicos - instrumentalizando a noçáo. McCarthy, Smith e Zald, por exemplo, entendem que a importância da mídia para os movimentos sociais 
está no fato de que esses atores necessitam influenciar as autoridades políticas e captar a atençáo do público - sendo que "a maior ferramenta neste processo são os meios de comunicação de massa, que podem atingir uma audiência muito maior do que os movimentos sociais podem atingir diretamente" (1996, p. 291). Para Klandermans e Goslinga (1996) o discurso midiático é uma importante fonte de informação, que baliza as interações e conversaçóes entre as pessoas. Porém, a mídia de massa é entendida como um espaço limitado e seletivo de transmissão de informação, que produz uma realidade divergente da que existe para os atores, constituindo-se assim em uma barreira para os movimentos sociais. Devido a esse panorama, esses atores necessitam empregar estratégias para "influenciar o curso da mídia" (KLANDERMANS; GOSLINGA, 1996, p. 324).

A concepção de comunicação da TMR é tâo instrumental quanto a sua própria noção de organização, que foi entendida como forma de mobilizar recursos econômicos, humanos e de comunicação para a ação (MCCARTHY; ZALD, 1977). Já as Teorias dos Novos Movimentos Sociais (TNMS), embora tenham problematizado pouco a comunicaçáo de forma direta, abriram espaço para pensá-la a partir de outra perspectiva ao conceberem os movimentos sociais enquanto redes de solidariedade: "[...] pequenos grupos imersos na vida cotidiana que requerem um envolvimento pessoal na experimentação e

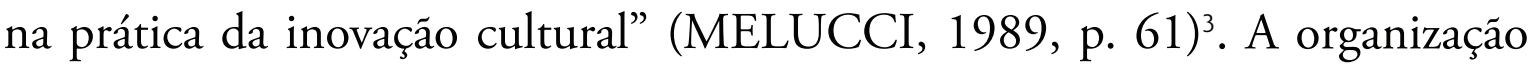
em rede é entendida, na grande parte dessas abordagens, não como um instrumento para alcançar um fim, e sim como a própria experimentação de outra sociedade. E nesse sentido, os códigos culturais e a constante reformulaçáo desses são o motor dos novos movimentos, sendo a comunicação, em sentido amplo e diverso, elemento central nessa tarefa.

A noção de identidade coletiva de Melucci (1996), por exemplo, como uma formulaçáo interativa e compartilhada que orienta as açóes, pressupóe um processo comunicativo dialógico entre os atores. Scherer-Warren (2008), ao abordar os quatro níveis constitutivos das redes de movimentos sociais (organizacional; narrativo e doutrinal; informação e comunicação; e social), nos deixa algumas pistas nesse sentido, explorando os processos interativos e subjetivos da constituição das redes dos movimentos sociais. A comunicação

3 Tradução da autora. 
é, em sua abordagem, a prática que permite às diversidades adaptarem-se em prol de entendimentos, narrativas, símbolos e açóes conjuntas. Para Scherer-Warren (2008), as NTICs, especificamente, facilitam a comunicaçáo inter-rede, a construção de redes de simpatizantes, a formação de uma opinião pública mundial e a difusão das narrativas e ideais.

Outra perspectiva que dialoga com as TNMS é a de Diani (2003), autor que tem trabalhado em prol de uma abordagem mais relacional sobre a ação coletiva. Ao contrário de Melucci (1989; 1996), que compreende as redes como forma de organização dos "novos movimentos sociais", Diani (2002) defende a centralização do conceito de redes nas abordagens dos atores "velhos" e "novos". Movimentos sociais como redes são "interaçóes informais entre uma pluralidade de indivíduos e grupos ou associações engajados em um conflito político ou cultural, tendo como base o compartilhamento de uma identidade coletiva” (DIANI, 2003, p. 301).

Diani (2002) sugere, assim, entender as redes como relação social. Nesse sentido, avança possibilitando reconhecer que as redes se configuram de diferentes formas, podendo ser "centralizadas ou descentralizadas", "segmentadas ou náo segmentadas" - ao contrário da abordagem da TNMS, que, em muitos momentos, associa as redes a uma organização horizontal e descentralizada (em oposição à organização hierárquica e vertical dos sindicatos operários). As redes se configuram de maneiras diferentes de acordo com cada contexto social, político e tecnológico. A comunicação, em Diani (2002), é o elemento que caracteriza os padróes estruturais das redes, que estáo baseados em duas variáveis: a "centralização" e a "segmentação". A centralização refere-se à tendência de que os fluxos de trocas e de comunicação se concentrem em atores específicos, afetando como os movimentos sociais operam e como constroem sua identidade. Já a segmentação refere-se à distância que separa os membros de uma rede ou, em outros termos, ao número de intermediários que separam dois atores da rede. A segmentação reflete assim as barreiras de comunicação entre os agentes. Embora traga contribuições, a noção do autor é demasiadamente estrutural, excluindo a dimensão simbólica e afetiva da comunicação.

Alguns investigadores, como Bimber et al. (2009) e Bennett e Segerberg (2012), vêm trabalhando especificamente sobre a relação entre as transformaçôes organizacionais na ação coletiva e as novas tecnologias da comunicação. Bimber et al. (2009) aponta que a internet tem possibilitado uma fecundidade 
das formas organizacionais, isto é, o desenvolvimento de formas organizacionais combinadas e distintas. O problema, a meu ver, é que esses autores só enxergam tal inovaçáo porque partem do pressuposto de que existia uma forma organizativa no passado, a descrita pela TMR.

Bennett e Segerberg (2012), em linha semelhante, distinguem entre duas lógicas de ação coletiva (que convivem hoje): a "ação coletiva", associada ao alto nível de organizaçáo de recursos e de identidade coletiva - explorada pelas TMR e TNMS; e a "ação conectiva", que se estrutura a partir da comunicação personalizada e da mídia digital. Nessa segunda, a organização da ação se dá pelo processo de difusão interativo e viral dos frames individuais. Essa abordagem tem dois problemas principais. Primeiro, foca excessivamente na atuação individual, o que é uma herança da TMR. O segundo refere-se a uma noção da comunicação muito restrita a lógica das redes sociais digitais, excluindo, por exemplo, as dinâmicas que ocorrem nas ruas. Bennett e Segerberg (2012) descrevem mais a lógica de difusão de conteúdos e informação do que de organização.

Devido a essas contribuiçóes e lacunas, a simbiose entre as formas de comunicação digitais e os processos organizativos contemporâneos é um campo ainda a ser explorado. Podemos destacar dois desafios para os estudos de ciberativismo nesse sentido. O primeiro deles é a necessidade de pensar a relaçáo entre organizaçáo e tecnologias a partir das relaçóes espacializadas dos atores, isto é, de suas realidades de lutas específicas, situadas no tempo e no espaço. Não há uma forma de organização para todos os movimentos sociais. As dinâmicas organizativas estáo associadas a outras dimensóes destes atores e do campo de luta no qual se inserem. Ao mesmo tempo, é necessário olhar para contextos históricos mais amplos, conectando a discussão às transformaçóes tecnológicas e sociais pelas quais passa a sociedade.

Como segunda tarefa, os estudos em ciberativismo precisam ultrapassar a associaçáo automática entre organização em rede e horizontalidade. Nos últimos anos, essa percepção caracterizou boa parte das descriçóes sobre o Zapatismo e do Movimento Antiglobalização, estando presente em noçóes como swarming (ARQUILLA; RONSFELD, 2000), smart mobs (RHEINGOLD, 2004) e autocomunicação das massas (CASTELLS, 2012). Na literatura mais recente sobre as mobilizaçóes pós-2010 ocorre algo similar. A horizontalidade estrutural da internet é associada aos movimentos sociais "espontâneos" 
e "sem liderança'. A internet favoreceria, nessas perspectivas, a colaboração e a solidariedade, restringindo a necessidade de uma liderança formal. Essa perspectiva, embora venha sendo debatida e questionada por alguns autores (NUNES, 2013; ROVIRA, 2009; SOARES, 2012), ainda merece discussóes.

\section{Difusão}

A difusão da ação coletiva pode ser entendida como o processo através do qual os repertórios de ação, as táticas, as estratégias, as ideias, os símbolos, as informaçôes técnicas, os discursos, as práticas e os valores se difundem de um movimento social para o outro ou/e de um lugar para o outro. A importância do tema para a sociologia dos movimentos sociais é que ele é transversal a várias dimensóes destes atores: "não se pode entender os movimentos sociais - como eles envolvem, como eles expandem, como eles engajam na arena política - sem compreender as dinâmicas de difusáo" (GIVANS; ROBERTS; SOULE, 2010, p. 1).

A noção de difusão ${ }^{4}$ está diretamente ligada a uma compreensão problemática de comunicação, o que explica grande parte das falhas nos trabalhos sobre o assunto. O termo remete a transmissão de informação e conhecimento, ao invés de um processo de interação dialógico e relacional. Está ainda relacionado a outras noçóes biológicas como contágio e viral, que ocultaram sua face interativa. Em consonância com essa nomenclatura, a literatura sobre o assunto tendeu a trabalhar o assunto de forma bastante rígida, a partir do modelo: transmissor, receptor, item difundido e canal de difusão (MCADAM; RUCHT, 1993; apud ROOS; OIKONOMAKIS, 2014). Nesse sentido, percebe-se uma relação entre a noção de difusão e os primeiros estudos sobre comunicação de massa.

Embora essa concepção de comunicação linear e não relacional tenha permeado a compreensão dos estudos da área, é fato que a comunicação como objeto foi muito pouco tematizada diretamente dentro dessas abordagens. Mesmo nos trabalhos que consideram a utilizaçáo da NTICs pelos ativistas como uma característica marcante da ação coletiva contemporânea, essa problematização inexiste. Esforços mais recentes têm tentando repensar a área de

4 Optamos por manter a utilização do termo a fim de dialogar criticamente com as Teorias dos Movimentos Sociais. 
debate a partir da combinação de alguns eixos básicos: o que é difundido; como a difusão ocorre; qual o impacto da difusão e porque a difusão acontece (DELLA PORTA; MATTONI, 2014; GIVANS; ROBERTS; SOULE, 2010). Embora nesse esquema as práticas e as ferramentas comunicativas utilizadas pelos ativistas, bem como os meios de comunicação mainstream, poderiam ser compreendidos enquanto mecanismos de difusão (mecanismos através dos quais a difusão ocorre), esse não tem sido um ponto amplamente explorado.

A partir desses apontamentos, gostaríamos de fazer um duplo esforço nessa seção: apontar as falhas na compreensão da comunicação incorporada nos estudos de difusão e sugerir que o estudo das práticas comunicativas dos ativistas, como mecanismo de difusáo, poderia, ao mesmo tempo, fortalecer uma nova noçáo de comunicação e ajudar a compreender as conexóes entre as lutas e os atores em um contexto cada vez mais globalizado e perpassado pelas tecnologias digitais.

No que tange ao primeiro ponto, Givans, Roberts e Soule (2010) reconhecem que os mecanismos de difusão revelam que essa não é um simples transplante de uma inovação de um lugar para o outro, mas, ao contrário, envolve um processo de adaptaçáo criativo e de aprendizagem política. Tarrow (2005a), em artigo do próprio livro organizado pelos três autores, tocando diretamente nessa problemática, destaca três mecanismos pelos quais a difusão acontece: relacionais, não relacionais e de mediação. Na classificação do autor, os meios de comunicação são mecanismos "não relacionais". A compreensão de relacional aqui está restrita ao contato face a face, o que é bastante questionável, sobretudo, no que tange à comunicação mediada pelas NTICs, que é cada vez mais interativa e instantânea. Além disso, o autor não distingue a internet de outros meios de comunicação de massa.

Chabot (2010), também criticando Tarrow (2010), afirma que o caminho escolhido pelo autor não permite compreender como as pessoas se envolvem nas dinâmicas de difusão. Com base nessa crítica, propôe uma abordagem dialógica. O diálogo, segundo Chabot (2010), envolve dois ou mais participantes ativos que contribuem com seus pontos de vistas e engajam-se nas questóes e 
respostas dos outros, expandindo os horizontes e transformando os pontos de vistas iniciais. Esse modelo de difusão dialógico baseia-se em quatro formas de comunicação: processo de tomada de consciência; processo de tradução; processo de experimentaçáo; processo de aplicação no movimento. Embora o autor olhe para o processo de difusáo a partir das experiências dos atores, adicionado certa personalidade a ele, a dinâmica que esquematiza ainda é muito linear e pouco dinâmica. Além disso, as tecnologias de comunicação não são o seu foco.

Vejamos como essas noçóes foram operacionalizadas nos estudos sobre os movimentos sociais ao longo do tempo. No caso dos movimentos mais clássicos, embora a noção de difusão não apareça como tal, ela pode ser pensada a partir do trabalho de propagação de ideias políticas realizado pelos sindicatos e partidos políticos através de panfletos, jornais e revistas. Os movimentos anarquistas são paradigmáticos nesse sentido, devido ao uso alternativo e criativo que realizaram dessas mídias, empregando padróes de publicação ligados aos princípios político-organizacionais do próprio movimento, como: não hierarquização, liberdade individual, pluralidade de opiniáo, não interferência comercial e governamental e produção através da cooperação voluntária (DOWNING, 2008).

Os impressos anarquistas estão espalhados por vários países da Europa, América e África Mediterrânea e constituem parte da própria história de imigração dos anarquistas e de difusáo dos seus ideais. No Brasil, as publicaçóes anarquistas desempenharam um grande papel na luta operária, devido à vinda de refugiados da Comuna de Paris de 1871 (RODRIGUES, 1997) e de imigrantes de Portugal, Espanha e Itália, no início da industrializaçãos. $\mathrm{O}$ anarquismo teve assim a importância não apenas na organização dos trabalhadores, mas também na fomentação de uma imprensa social no Brasil.

Já durante o século XX surgiram alguns estudos específicos sobre a mídia como mecanismo de difusão, influenciados pela eclosão dos meios de comunicação de massa (rádio, televisão, cinema) e pelas abordagens sobre a "comunicação de massa”. Nesse contexto, algumas teorizaçóes sobre os movimentos

5 Esses quatro paises foram locais onde o anarquismo se refugiou após a extinção da Internacional em 1876, advinda do ápice das discordâncias entre Marx e Bakunin sobre a melhor forma de organizar os operários (GIANNOTTI, 2007). 
sociais passaram a questionar como os meios de comunicação de massa intervinham nas dinâmicas de difusão da ação coletiva. Isso se dava de duas maneiras principais: através da seleção do que é noticiado, dado que os veículos privilegiam noticiar eventos com maior número de pessoas (MCCARTHY; SMITH; ZALD, 1996); e de acordo coma distribuição da mídia, uma vez que a imprensa privilegia reportar eventos que ocorrem próximos às sedes midiáticas (ANDREWS; BIGGS, 2006). O problema, na maior parte das abordagens, aqui exemplificadas com esses dois casos, é que a relação entre comunicação e difusão ficou restrita às coberturas midiáticas dos protestos, realizadas pelos veículos mainstream. Além disso, imperou uma compreensão da comunicaçáo como transmissáo de informaçóes e conhecimento, que permeia ainda alguns estudos contemporâneos.

A partir da entrada em cena da internet alguns autores têm ressaltando que as NTICs estão alterando a dinâmica de difusão tornando-a mais rápida e eficiente (AYRES, 1999; GLASIUS; PLEYERS, 2013) e modificando suas as dinâmicas. Ayres (1999) chega a sugerir que a internet permite que a difusão aconteça sem a necessidade de conexóes culturais e redes interpessoais previamente consolidadas, como se isso fosse possível. Autores como Roos e Oikonomakis (2014) têm apontado justamente o contrário, isto é, a importância da pré-existência de rede de movimentos e ativistas para que a difusão ocorra. Gerbaudo (2013), em um dos poucos trabalhos que se debruçam sobre o tema especificamente, aponta que as dinâmicas de difusão dos repertórios e frames entre os países onde ocorreram os protestos Primavera Árabe, Indignados (Espanha e Grécia) e Occupy (EUA), foi lenta e tortuosa devido à complexidade da tradução necessária para o diálogo entre contextos culturais tão distintos:

However, compared to 1848 or other important revolutionary waves, such as 1968 or 1989 , what is striking about the 2011 wave is its rather slow and convoluted progression. This sluggishness in protest transmission bespeaks a complexity in translating the collective action frames and protest repertoires from one area to another and the continuing importance of cultural contexts. Despite assumptions about the globally interconnected character of our contemporary lives, increasingly facilitated by the penetration of social media, the protest wave of 201 I shows that the world continues to be marked by a number of cultural barriers (national, linguistic, religious) that constitute a serious obstacle to the transmission of protest cultures across different countries (GERBAUDO, 20I3, p. 87).

Outros estudos têm tangenciado a questão do papel da internet na difusão dos protestos contemporâneos a partir da análise de dados da internet 
(big data). Como exemplo, temos a pesquisa que buscou analisar o papel dos ativistas, da imprensa e das celebridades na difusão de informaçóes, a partir do Twitter, sobre os protestos ocorridos em junho de 2013 no Brasil, (ZAGO; RECUERO; BASTOS, 2014). No plano internacional, os pesquisadores do grupo "Datanalysis 15M", que investigam o movimento espanhol conhecido como 15M/Indignados, analisaram, dentre outras questóes, os processos de difusão das "táticas e estratégias de utilização das redes digitais e identidades coletivas para gestar, organizar e dar sentido as ações políticas" (DATANALYSIS15M, 2013, p. 4) - a partir de dados do Twitter. O foco dessas pesquisas e outras que analisam dados das redes sociais é a difusão de informação/ mensagens entre os perfis e não a difusão enquanto processo mais amplo de compartilhamento de aprendizados, símbolos, bandeiras, slogans, formas de organizaçóes. Além disso, cabe distinguir o que são perfis de redes sociais, sejam eles individuais ou coletivos, de movimentos sociais. Se por um lado os estudos baseados em big data buscam dar conta das informaçóes produzidas pelos usuários na internet (que podem e devem ser utilizados de forma complementar a outras análises da ação coletiva), por outro, restringem as observaçôes às dinâmicas digitais, como se as páginas das redes sociais e os sites fossem equivalentes aos atores (ativistas e movimentos sociais).

$\mathrm{Na}$ literatura sobre ação coletiva e movimentos sociais, o tema da difusão vem sendo trabalhado, ainda que de forma indireta, pelas pesquisas do Contentious Politics, que exploraram as dinâmicas globais do ativismo, através da noção de mudanças de escalas da ação coletiva (TARROW, 2005b), entendendo-a como um processo no qual padróes de açóes e organizaçóes nacionais excedem-se para contextos internacionais quando se abrem oportunidades políticas (MCDONALD, 2006). No entanto, dentre as lacunas ainda a serem exploradas, está o papel da comunicaçáo digital nessa mudança de escalas. Além disso, uma noção relacional de difusão contribuiria para que esse processo fosse compreendido de maneira mais dinâmica e relacional.

\section{O ciberativismo: uma configuração comunicativa dos movimentos sociais}

Ao longo desse trabalho buscamos apontar como a comunicaçáo perpassa todas as dinâmicas da ação coletiva e dos movimentos sociais, descortinando lacunas dos estudos sobre a ação coletiva e esses atores. No entanto, não 
partimos de uma definição fechada do conceito de comunicação, embora tenhamos buscado nos afastar de sua compreensão como transferência de conhecimento e informaçáo sobre o mundo e as pessoas. Por outro lado, procuramos nos aproximar de um entendimento da comunicaçáo como "um processo de organização de perspectivas compartilhadas, sem o que nenhuma ação, nenhuma interação é possível" (QUERE, 1991, p. 10).

O olhar histórico nos permitiu desmistificar a "novidade" do ciberativismo, dado que a dimensão comunicativa não é um elemento novo para os movimentos sociais. Esses atores utilizaram outras tecnologias de comunicaçáo ao longo do tempo e, além disso, a comunicação, entendida de forma mais ampla, enquanto prática constituinte da vida social, náo se restringe aos instrumentos tecnológicos. Por outro lado, podemos apontar o ciberativismo como uma nova configuração comunicativa dos movimentos sociais, caracterizada pela reestruturação das práticas cotidianas de comunicação, por interaçóes mediadas pelas NTICs e pela conexão digital entre indivíduos, grupos e sociedade. Esse novo padrão comunicativo implica na geração de novas dinâmicas de confronto, temporalidades e espacialidades para a ação coletiva contemporânea, assim como de subjetividades políticas.

O esforço teórico-analítico aqui realizado, de pensar as práticas e as teorizaçóes sobre os movimentos sociais a partir da comunicação como um denominador comum, nos permitiu amadurecer as noçóes de repertório, organização e difusão para entender os fenômenos contemporâneos da ação coletiva de modo mais relacional. Apontamos que os repertórios são criados a partir da relação e interaçáo entre os atores no confronto político e, nesse sentido, que a criaçáo das formas de açáo é produto de um processo de aprendizagem e de criatividade dos atores em conjunto. Com base nessa perspectiva coloca-se em questionamento as interpretaçóes que enxergam a emergência de um novo repertório a cada novo uso de uma plataforma de comunicação ou de uma tecnologia. Por trás da identificação de um novo repertório está a existência das transformaçóes internas e externas dos movimentos, que impulsionam a externalização da ação coletiva em outras frentes e formas. No entanto, a externalização da ação coletiva via mídias sociais, em seu conjunto, é algo que ainda precisa ser compreendido a partir do seu significado para os próprios atores e em seu contexto sociopolítico. 
Com a análise dos estudos sobre organização dos movimentos sociais, colocou-se em evidência que as noçóes de organização estiveram relacionadas a distintas compreensóes de comunicaçáo. Apontou-se que, nos últimos anos, os processos organizativos têm sido observados a partir das dinâmicas comunicativas geradas pela internet e por outras NTICs. Algumas análises têm tomado erroneamente como pressuposto que a arquitetura em rede distribuída da internet garante características como horizontalidade, ausência de liderança e espontaneidade aos movimentos sociais. Na verdade, o que se tem observado é a geração de outras práticas organizativas, o surgimento de novos tipos de liderança e o deslocamento da tensão entre horizontalidade/ verticalidade para outras esferas. Para além disso, os ativistas utilizam várias tecnologias e interagem com diferentes meios de comunicação e profissionais de comunicação, ao mesmo tempo.

A análise dos aspectos de difusão da ação coletiva é a que revela, de maneira mais explicita, a instrumentalização da noção de comunicação nos estudos sobre os movimentos sociais. Tanto a difusáo da ação coletiva como a comunicação foram entendidas, na maior parte das vezes, como uma transmissão de informação ou conhecimento. No entanto, pensar os processos de difusão da ação coletiva é uma tarefa necessária para a compreensão das dinâmicas, práticas e gramáticas do ativismo global contemporâneo. Dada a própria transversalidade do tema da difusáo, os estudos sobre o assunto podem contribuir para a construção de uma perspectiva comunicacional e relacional da ação coletiva e dos movimentos sociais, caso entendamos a comunicação de forma dialógica.

Por fim, ao olhar para estes três eixos a partir da comunicação, ressalta-se como a ação coletiva e os atores são construídos a partir da combinação de um conjunto de variáveis. Nesse sentido, análises dos movimentos socais e da ação coletiva a partir da comunicação podem ajudar a compreender esses atores e processos de forma mais complexa e relacional, em suas múltiplas nuances. Algumas pistas nessa direção podem ser encontradas em Juris (2008, 2012) e em Kavada (2013), que argumentam no sentido de que a "lógica cultural" ou a "cultura comunicacional", respectivamente, não existem em um vácuo, estando, ao contrário, relacionadas a práticas, crenças, identidades coletivas e processos organizativos dos movimentos. O que a análise dos três eixos realizada nesse artigo permite é justamente observar como a comunicação está ligada a outros componentes dos movimentos sociais e da açáo coletiva. 


\section{Referências}

ANDREWS, K.; BIGGS, M. The dynamics of protest diffusion movement: organizations, social networks, and news media in the 1960 sit'ns. American sociological review, v. 71, p. $752-777,2006$.

ARQUILLA, J.; RONSFELD, D. Swarming and the future of conflict. USA: Rand Corporation, 2000.

ATTON, C. Alternative media. [s.l.] Sage Publications, 2002.

AYRES, J. M. From the streets to the internet. American Academy of Political and Social Science, The cyber-diffusion of contention, p. 132-143, 1999.

BENNETT, W. L.; SEGERBERG, A. The logic of connective action: digital media and the personalization of contentious politics. Information, communication e society, v. 15, n. 5 , p. 739-768, 2012.

BIMBER, B.; STOHL, C.; FLANAZIN, A. J. Technological change and the shifting nature of political organization. In: CHADWIKC, A.; HOWARD, A. (Org.). Routledge handbook of internet politics. London: Routledge, 2009. p. 72-85.

BOASE, J.; WELLMAN, B. Personal relationships: on and off the internet. In: VANGELISTI, A. L.; PERLMAN, D. (Org.). Handbook of personal relations. [s.l.] Cambridge University Press, 2006.

BRINGEL, B. Com, contra e para além de Charles Tilly: mudanças teóricas no estudo das açôes coletivas dos movimentos sociais. Sociologia \& antropologia, v. 2, n. 3, p. 43-67, 2012.

CAMMAERTS, B.; MATTONI, A.; MCCURDY, P. (ORG.). Mediation and protest movements. UK: Hobbs, 2013.

CARROLL, W. K.; HACKETT, R. A. Democratic media activism through the lens of social movement theory. Media, culture \& society, v. 28, n. 1, p. 83-104, 2006.

CASTELLS, M. Redes de indignación y esperanza los movimientos sociales en la era de internet. Madrid: Alianza Editorial, 2012.

CHABOT, S. Dialogue matters: beyond the transmission model of transnational diffusion between social movements. In: GIVANS, R.; ROBERTS, K.; SOULE, S. (Org.). The diffusion of social movements: actors, mechanisms and political effects. [s.l.] Cambridge University Press, 2010. p. 99-124. 
DATANALYSIS15M. Tecnopolítica: la potencia de las multitudes conectadas. El sistemared 15M como nuevo paradigma de la política distribuida. 2013. Disponível em: <http:// datanalysis $15 \mathrm{~m}$.files.wordpress.com/2013/06/tecnopolitica-15m-resumen.pdf>. Acesso em: 14 nov. 2014.

DELLA PORTA, D.; MATTONI, A. (ORG.). Spreading protest social movements in times of crisis. [s.l.] ECPR Press, 2014.

DIANI. Networks and social movements: a research programme. In: DIANI, M.; MCADAM, D. (Org.). Social Movements and Networks: relational Approaches to Collective Action. Nova York: Oxford University Press, 2003. p. 299-319.

DOWNING, J. et al. Radical media rebellious communication and social movements. EUA: Sage Publications, 2001.

Social movement theories and alternative media: an evaluation and critique. Communication, culture \& critique, p. 40-50, 2008.

GARRETT, K. R. Protest in an Information: a review of literature on social movements and new ICTs. Information, communication and society, v. 9, n. 2, p. 202-224, 2011.

GERBAUDO, P. Protest Diffusion and Cultural Resonance in the 2011 Protest Wave. The international spectator: Italian Journal of International Affairs, v. 48, n. 4, p. 86-101, 2013.

ERBAUDO, P.; TRERÉ, E. In search of the "we" of social media activism: introduction to the special issue on social media and protest identities. Information, communication \& society, v. 18 , n. 8 , p. $864-871,2015$.

GIANNOTTI, V. História das lutas dos trabalhadores no Brasil. Rio de Janeiro: Mauad, 2007.

GIVANS, R.; ROBERTS, K.; SOULE, S. The diffusion of social movements actors, mechanisms and political effects. [s.l.] Cambridge University Press, 2010.

GLADWELL, M. A revolução não será tuitada. Observatório da Imprensa, de dezembro de 2010. Acesso em: 5 ago. 2015.

GLASIUS, M.; PLEYERS, G. The global moment of 2011: democracy, social justice and dignity. Development and change, p. 547-567, 2013.

JURIS, J. S. Networking futures the movements against corporate globalization. United States of America: Duke University Press, 2008.

Reflections on \#Occupy Everywhere: social media, public space, and emerging logics of aggregation. American ethnologist, v. 29, n. 2, p. 259-279, 2012. 
KAVADA, A. Internet cultures and protest movements: the cultural links between satrategy, organizing and online communication. In: CAMMAERTS, B.; MATTONI, A.; MCCURDY, P. (Org.). Mediation and protests movements. UK: Intellect, 2013. p. 75-94.

KLANDERMANS, B.; GOSLINGA, S. Media discourse, movement publicity, and the generation of collective action frames. Theoretical and empirical exercises in meaning construction. In: MCADAM, D.; MCCARTHY, J. D.; ZALD, M. N. (Org.). Comparative Perspectives on social movements: political opportunities, mobilizing structures, and cultural framings. [s.1.] Cambridge University Press, 1996. p. 312-337.

LAER, J. V.; AELST, P. V. Internet and social movement action repertoires. Information, communication \& society, v. 13, p. 1146-1171, 2010.

LANGMAN, L. From virtual public spheres to global justice: a critical theory of internetworked social movements. Sociological theory, v. 23, n. 1, p. 42-74, 2005.

LENIN, V. I. Que fazer?. [s.l.] The Marxists Internet Archive, 1902.

MAIA, R. C. M. Atores da sociedade civil e ação coletiva: relaçóes com a comunicação de massa. Lua nova, n. 76, p. 87-118, 2009.

MCADAM, D.; RUCHT, D. The cross-national diffusion of movement ideas. Annals of the american academy of political and social science, n. 528, p. 56-87, 1993.

MCCARTHY, J. D.; SMITH, J.; ZALD, M. Assessing public, media electoral, and governamental agendas. In: MCADAM, D.; MCCARTHY, J. D.; ZALD, M. (Org.). Comparative perspectives on social movements: political opportunities, mobilizing sctructures, and cultural framings. [s.1.] Cambridge University Press, 1996. p. 291-311.

MCCARTHY, J. D.; ZALD, M. Resource mobilization and social movements. American journal of sociology, n. 82, p. 1212-1241, 1977.

MCDONALD, K. Global movements action and culture. [s.l.] Blackwell Publishing, 2006.

MELUCCI, A. Um objetivo para os movimentos sociais? Lua nova, p. 49-66, 1989.

NUNES, R. G. A organização dos sem organização: oito conceitos para pensar o "inverno brasileiro". Le Monde Diplomatique Brasil, ago. 2013. Disponível em: <http://www. diplomatique.org.br/acervo.php?id=3036>. Acesso em: 2 dez. 2015.

PEREIRA, M. A. G. Cyberactivismo e democracia: movimentos sociais e novos repertórios de acçáo. 2008. Tese (Doutorado em Sociologia) - Faculdade de Economia, Universidade de Coimbra, Coimbra, 2008. 
PERUZZO, C. M. K. Comunicaçáo nos movimentos populares: a participação na construção da cidadania. 3. ed. São Paulo: Vozes, 2004.

QUERE, L. De um modelo epistemológico da comunicação a um modelo praxiológico. Réseaux, n. 46-47, 1991.

RHEINGOLD, H. Multitudes inteligentes la próxima revolución social. Barcelona: Gedisa, 2004.

RODRIGUES, E. Pequena história da imprensa social no Brasil. Florianópolis: Insular, 1997.

ROOS, J. E.; OIKONOMAKIS, L. They don't represent us! The global Resonance of the Real Democracy Movement from the Indignados to Occupy. In: DELLA PORTA, D.; MATTONI, A. (Org.). Spreading protest: social movements in times of crisis. [s.l.] ECPR Press, 2014.

ROVIRA, G. Zapatistas sin frontera. México: Era, 2009.

SADER, E. Quando novos personagens entram em cena: experiências, falas e lutas dos trabalhadores da Grande São Paulo (1970-80). Rio de Janeiro: Paz e Terra, 1988.

SCHERER-WARREN, I. Redes de movimentos sociais na América Latina: caminhos para uma política emancipatória? Caderno CRH, v. 21, n. 54, p. 505-517, 2008.

SOARES, C. C. Sobre o significado da experiência de autogoverno zapatista. 2012. Tese (Doutorado em Sociologia) - Instituto de Estudos Sociais e Políticos, Universidade do Estado do Rio de Janeiro (UERJ), Rio de Janeiro, 2012.

TARROW, S. Diffusion and modularity. In: The new transnational activism. Cambridge: Cambridge University Pres, 2005a.

The new transnacional activism. United States of America: Cambridge University Press, 2005b.

O poder em movimento: movimentos sociais e confronto político. Petrópolis: Vozes, 2009.

TILLY, C. From mobilization to revolution. Reading, MA: Addison-Wesley, 1978. Contentious Repertoires in Great Britain, 1758-1834. Social science history, v. 17, n. 2, p. 253-280, 1993.

Repertoires of Contention. In: Regimes and repertoires. EUA: The University of Chicago Press, 2006. p. 30-59. 
TRERÉ, E. Más allá de la concepción instrumental de la comunicación en los movimientos sociales: los medios como prácticas en el ecosistema comunicativo. In: AMEZCUA, V. del C. M. (Org.). Comunicación y cultura. Querétaro, México: Universidad Autónoma de Querétaro/ Facultad de Ciencias Políticas y Sociales, 2014.

ZAGO, G.; RECUERO, R.; BASTOS, M. T. Quem retuita quem? Papeis de ativistas, celebridades e imprensa durante os \#protestosbr no Twitter. In: XXIII ECONTRO ANUAL DA COMPÓS. Pará, a 30 de maio de 2014.

\section{Ciberativism and the Communicative Dimension of Social Movements: repertoires, organization and dissemination}

\section{Abstract}

Important updates of Social Movements Theories from the communicative aspects of collective action have been held around the discussions relating to cyberactivism - reducing the gap between studies in communication and social movements. However, much of the work can be characterized by an excessive focus on the technologies and in an instrumentalization of the concept of communication. This article rethinks the theories of collective action and social movements from the communication's perspective, performing two efforts: firstly through an historical analysis, which seeks to demonstrate the centrality of communicative dimensions in the practices of social movements before the growth of internet, building a non-instrumental perspective of the communication; second, it proposes an interpretation of theoretical bias that enables a look in an integrated manner to three analytical axes of theories of collective action and social movements: the repertoires of collective action, organization processes and the diffusion's dynamics.

Keywords: Cyberactivism. Digital communication. Social movements. Sociology of social movements.

Recebido em 10/03/2016

Aceito em 25/11/2016 